\title{
Pharyngeal swallowing phase and chronic cough
}

\author{
Daniela Rejane Constantino Drozdz', Cintia Conceição Costa², Paulo Roberto de Oliveira Jesus ${ }^{3}$, Mateus Silva Trindade ${ }^{4}$, \\ Guilherme Weiss ${ }^{5}$, Abdias Baptista M. Neto ${ }^{6}$, Ana Maria T. da Silva ${ }^{7}$, Renata Mancopes ${ }^{8}$.
}

1) Speech Language Pathologist, Specialist in Oral Motricity approach with hospital. Master student of the Post-graduation Program in Human Communication Disorders, Federal University of Santa Maria (UFSM), Santa Maria, Rio Grande do Sul.

2) Speech Language Pathologist post-graduation. Master student of the Post-graduation Program in Human Communication Disorders, Federal University of Santa Maria Santa Maria (UFSM), Santa Maria, Rio Grande do Sul, Brazil.

3) Radiologist Doctor. Chief of the Radiology service of the Academic Hospital of Santa Maria (HUSM), Santa Maria, Rio Grande do Sul, Brazil.

4) Radiology Technician.

5) Physical Specialist in Radiology Diagnostic by the ABFM. Physical specialist in radiology diagnostic by the ABFM.

6) Pulmonologist Doctor.

7) Speech Language Pathologist (SLP); Associate Professor of the Phonoaudiology Department of the Federal University of Santa Maria (UFSM), Santa Maria, Rio Grande do Sul, Brazil, PhD.

8) Speech Language Pathologist (SLP), Adjunct Professor of the Post-Graduation Program in Human Communication Disorders, Santa Maria (UFSM), Santa Maria, Rio Grande do Sul, Brazil, PhD.

Institution: Universidade Federal de Santa Maria. Santa Maria / RS - Brazil.

Mailing address: Daniela Rejane Constantino Drozdz - Avenida Fernando Ferrari, 1220 - Apto. 302 - Santa Maria / RS - Brazil - Zip code: $97050-801$ - E-mail: danidrozdz@hotmail.com

Article received in June 30, 2012. Article approved in August 26, 2012.

\section{SUMMARY}

Introduction: The act of swallowing depends on a complex and dynamic process which uses common structures to the act of breathing; respiratory problems can cause swallowing difficulties.

Aim: To assess the swallowing pharyngeal phase in patients with chronic cough.

Method: Retrospective study with 15 patients of both genders, patients with chronic cough and risk factors for aspiration defined by the pneumologic diagnosis. The patients were submitted to anamnesis on complaints related to swallowing, chewing and breathing, or related to food and to videofluoroscopic examination.

Results: It was observed that $33.3 \%$ had normal and functional swallowing, being the last one of most prevalence. The mild dysphagia was observed in $20 \%$ of the patients, the mild to moderate dysphagia in $6.7 \%$ of them. In relation to the Rosenbek scale, $73.3 \%$ of patients presented degree 1, 6.7\% presented degrees 2 and 3, and $13.3 \%$ presented degree 8 . The most found pathology was the chronic cough with $40 \%$, followed by asthma with $20 \% ; 69.2 \%$ of patients presented stasis and of these, five used protection maneuvers, of these, seven were effective and only three were used in the presence of stasis. The most used maneuver was the multiple swallowing, being effective in 100\%.

Conclusion: There are peculiarities in the patients' swallowing with chronic cough that, although not presenting complaints relating to swallowing, it presents an important aspiration risk due to the presence of changes in breathing pattern that can intervene in the coordination between breathing and swallowing, which is essential to protect the lower airway.

Keywords: deglutition disorders; fluoroscopy; methods; cough.

\section{INTRODUCTION}

The act of swallowing is a vital function to human beings, although it seems simple, it is a highly complex and dynamic process, which structures and systems involved are common to the act of breathing, being of extremely importance for the nutrition of the organism as a whole $(1,2)$. During swallowing, the food will be transported from the mouth to the stomach, without occurring during this process, the entry of substances into the airway, for this, it is required for the individual to have a precise coordination, especially between the oral and pharyngeal phases (2).

In general, swallowing can be divided into four phases: preparatory phase, oral phase, pharyngeal phase and oesophageal phase (3). The pharyngeal phase is sorted as the main pharyngeal during swallowing, as there is involvement of the oral cavity part, of the masticatory muscles and of the intrinsic and extrinsic muscles of the larynx (4).

In some cases, the physiological process of swallowing can be adjusted either by mechanical causes, such as neurological causes, characterizing thus the clinical picture of dysphagia (5).

The patient with a clinical picture of dysphagia may present several changes in the act of swallowing, including: inability to handle food; trouble for keeping the food in the mouth, difficulty controlling the saliva, coughing before, during and after swallowing, recurrent pneumonias; weight 
loss without definite reason, choking and suffocation, among other changes $(1,2,6)$.

At presenting clinical evidences for the diagnosis of dysphagia, the patient must be referred to an objective instrument assessment. This may be the videofluoroscopy (VFL) which is a radiological method that allows the evaluation of all phases of swallowing dynamically and it is considered the gold standard for diagnosis and treatment of oropharyngeal dysphagia $(7,8)$. During the performance of this examination, it is observed the presence of aspirations which may be asymptomatic (9), demonstrating thus the need for an evaluation of swallowing dysfunction in such patients (10).

Moreover, the indication of this test aims to determine the effectiveness of the rehabilitation strategies and to provide a pre- and post-therapy visual feedback (11).

Aspiration is defined as the inhalation of an oropharyngeal or gastric content into the larynx and into the lower respiratory tract (10). This material (bacteria, stomach acid, food particles and foreign bodies) can cause to an individual, a lung disease and its severity depends on the suctioned amount. Among the most common forms of aspiration lung disease, there are found: bronchiectasis, abscesses and interstitial fibrosis (12).

It is observed in this case, the interest of the pulmonologists and Speech Language Pathologists in the complications arising from dysphagia (4), as patients with chronic lung disease present changes in the coordination of the respiratory cycle with the swallowing, and this disruption may increase the risk of aspiration in patients on the advanced stage of the disease, thus contributing to exacerbations (13).

It is common in these patients the presence of chronic cough, which is characterized by the presence of cough for more than three weeks. It is believed that it is often related to the post nasal drip, to asthma, to the gastroesophageal reflux, to chronic bronchitis and to bronchiectasis (14).

Clinical and research evidences demonstrate that by using systematic programs of screening, diagnosis and dysphagia treatment, there is a significant reduction in the rates of aspiration pneumonia (15).

Thus the speech pathology intervention in hospitals enables an early evaluation and a differential diagnosis in cases of dysphagia, aiming to prevent, avoid and/or minimize the clinical complications of the patient (16).

The speech pathology assessment, therefore, must consider the patient's overall clinical status and the presence of lung disorders associated with complaints of swallowing or presence of chronic cough, which will allow the proper formulation of diagnostic hypotheses about aspiration risk in these cases.

The objective of this study is to analyze the pharyngeal phase of swallowing in patients with chronic cough.

\section{METHOD}

This is a retrospective, cross-sectional, population study and of quantitative character. The same was done at a University Hospital of Rio Grande do Sul, during the period from September 2011 to February 2012.

The sample comprised 15 patients with an average age of 67.1 years, of both genders, patients with chronic cough ( $>8$ weeks of duration) and with risk factors for aspiration, defined by the pneumologic diagnosis as patients with chronic cough and/or respiratory symptoms. They were referred by the teams of pulmonology and speech pathology.

All subjects received instructions about the objectives, justification and methodology of the proposed study and signed a Free and Informed Consent Form.

The patients were subjected to anamnesis, to obtain information about complaints in relation to swallowing, chewing, breathing, and related to the feeding moment.

It was performed the videofluoroscopy (VFL) examination using the videofluoroscopy protocol usual of the service, which includes the analysis of food intake contrasted in the liquid, nectar, honey pudding and solid consistencies. For liquid consistency, it was added water to the liquid barium (Bariogel ${ }^{\circledR}$ ), in a proportion of one to one ( $15 \mathrm{ml}$ water to $15 \mathrm{ml}$ of barium); in nectar, there were used $30 \mathrm{ml}$ of liquid barium, for the honey it was used $15 \mathrm{ml}$ of water and $15 \mathrm{ml}$ of barium and one $3 \mathrm{ml}$ tablespoon of thickener (Thick and up ${ }^{\circledR}$ ), for the pudding, it was used $15 \mathrm{ml}$ of water, $15 \mathrm{ml}$ of barium and $5 \mathrm{ml}$ of thickener and for the solid, it was used bread soaked with barium (17).

When performing the VFL, individuals remained seated and the capturing of pictures was made in the lateral-lateral position, fluoroscopic image focus previously defined by the lips, superiorly by the hard palate, then by the posterior pharyngeal wall and inferiorly by the bifurcation of the airway and oesophagus (at the height of the 7 th cervical vertebra). Initially, there were offered the liquid and nectar consistencies in the $5 \mathrm{ml}$ spoon and in free sips 
respectively then were offered the honey and pudding consistencies in the $5 \mathrm{ml}$ spoon and finally the solid consistency with the ingestion of bread.

All examinations were performed by two Speech Language Pathologists, and a radiology technician. The images of videofluoroscopy were obtained using a Siemens equipment, Axiom Iconos R200 model, being captured and recorded by the ZScan6 Gastro software - Version: 6.1.2.11, installed on the Itautec Infoway computer, Windows 7, Intel Pentium P6200, which resulted in an average exposure of $0.14 \mathrm{mR} /$ frame.

For purposes of this study, there were analyzed: gender, degree of dysphagia, the presence/absence of penetration and/or laryngeal aspiration, the presence/ absence of stasis, the use of therapeutic maneuvers, types of used maneuvers and their effectiveness.

The data used in this study are part of a project previously approved by the Ethics Committee in Research of the Federal University of Santa Maria - CEP/UFSM under the protocol number 23081.013174/2011-46.

\section{RESULTS}

In order to meet the objectives proposed in this study, there were considered several statistical techniques of the chi-square and the Speerman correlation. Initially, it was performed a descriptive analysis of all the variables in order to obtain the profile of patients attended in the service. For nominal variables, it was performed the chisquare test, which verified the relationship of these variables with the diagnosis; now for the ordinal variables, it was used the Spearman correlation test. It was adopted a significance level of $5 \%(0.05)$.

The related data were processed and analyzed in electronic form from the construction of a database (Excel 2007) and of an analysis specific program to meet the research objectives, the Statistical Package software for Social Science 15.0 (SPSS).

Out of the 15 patients that participated of the survey, the average age was of 67.1 years, $53.3 \%$ were women and $46.7 \%$ were men.

The profiles of the patients according to the variables of the pharyngeal phase are shown in Tables 1, 2 and 3 below:

The dysphagia can be classified into seven degrees (18). Concerning the degree of dysphagia in this sample, it was observed that $33.3 \%$ had degree 7 (normal swallowing) and degree 6 (functional swallowing), being the last one of the most prevalence. The degree 5 (mild dysphagia) was observed in $20 \%$ of the patients, being found $6.7 \%$ in the degrees 4 (mild to moderate dysphagia) and 3 (moderate dysphagia) respectively. There were not found patients in the degrees 2 and 1 (moderate to severe dysphagia and severe dysphagia) (Table 1).

As regards to the analysis of laryngeal penetration and aspiration (19), it was observed that most of the patients $(73.3 \%$ ) had degree 1 (no entry of contrast in the airway), while $6.7 \%$ had the degrees 2 (contrast enters above the vocal folds, without residue) and 3 (contrast remains above the vocal folds with residue). The degree eight (contrast passes to the glottis is no response from the patient) was found $13.3 \%$ of patients (Table 2 ).

The most commonly found pathology of pneumologic origin during the visits was chronic cough

Table I. Dysphagia degree*.

\begin{tabular}{ccc}
\hline Dysphagia degree & Patients & $(\%)$ \\
7 & 5 & 33,3 \\
6 & 5 & 33,3 \\
5 & 3 & 20,0 \\
4 & 1 & 6,7 \\
3 & 1 & 6,7 \\
\hline Total & 15 & 100 \\
\hline
\end{tabular}

*Classification according to O'NEIL et al, $1999^{13}$.

Table 2. Rosenbeck scale*.

\begin{tabular}{ccc}
\hline Rosenbeckscale & Patients & $(\%)$ \\
\hline 1 & II & 73,3 \\
2 & 1 & 6,7 \\
3 & 1 & 6,7 \\
8 & 2 & 13,3 \\
\hline Total & 15 & 100 \\
\hline
\end{tabular}

* Rosenbeck scale et al,1996 ${ }^{18}$.

Table 3. Description of lung disorders that were found in the assessed patients.

\begin{tabular}{lcc}
\hline Pathologies & Patients & $(\%)$ \\
\hline ASTHMA & 3 & 20,0 \\
Chronic cough & 6 & 40,0 \\
Emphysema & 1 & 6,7 \\
Pulmonaryfibrosis & 1 & 6,7 \\
Pneumonia & 1 & 6,7 \\
Bronchiectasis & 2 & 13,3 \\
COPD & 1 & 6,7 \\
\hline \multicolumn{1}{c}{ Total } & 15 & 100 \\
\hline
\end{tabular}


with $40 \%$, followed by the asthma with $20 \%$. Apart from these, other pathologies amounted $46.8 \%$ of the sample and included: pulmonary emphysema, pulmonary fibrosis, pneumonia, bronchiectasis and COPD (Table 3).

In Table 4, it is presented the presence of stasis during swallowing and it is observed the use, type and effectiveness of the maneuvers for this variable.

Out of the fifteen patients, nine (60\%) showed stasis and of these, five used protection maneuvers. Concerning these maneuvers: seven were effective, but only three were used in the presence of the stasis. Among these maneuvers, the most used was the multiple swallowing, being effective in $100 \%$ of the cases.

In Table 5, it is observed the correlation between the variables: degree of dysphagia, Rosenbeck scale (19), presence of penetration or aspiration.

There was significant negative correlation between the Rosenbeck scale (18) and the degree of dysphagia. This is explained by the relationship of inversion between the adopted classes. That is, the worse the degree of dysphagia (18) the lower will be the number on that scale and in the classification of the degree of penetration/ aspiration (19); the worse the penetration/aspiration the greater will be the number on this scale.

In addition, in this sample, it was possible to verify that there was a significant negative correlation between the degree of dysphagia and the presence of penetration and aspiration, showing that the smaller the degree of dysphagia, the higher is the presence of penetration and aspiration.

In Table 6 it is observed that there was no correlation between the variables: stasis, Rosenbeck scale (19), and presence of penetration or aspiration.

\section{DisCUSSION}

In cases of patients with chronic cough, the doctor must through their clinical judgment to identify patients who are at risk of aspiration and direct them to a swallowing assessment, and also for the VFL examination (20), since the presented evidences demonstrate difficulties in swallowing and aspiration risk in this sample.

Regarding gender, a study (21) investigated asymptomatic men and women through the VFL and can observe that the differences found in swallowing could be more related to the anatomy than to a dysfunction, as the physiological system can perform its function with certain
Table 4. Statistical analysis of the stasis presence in relation to the: use of maneuvers, effectivemaneuver, type of maneuver and gender.

\begin{tabular}{|c|c|c|c|}
\hline \multirow[t]{2}{*}{ Variables } & \multicolumn{2}{|c|}{ Stasis } & \multirow[t]{2}{*}{$p$-value } \\
\hline & $\begin{array}{c}\text { Presence } \\
N(\%)\end{array}$ & $\begin{array}{l}\text { Absence } \\
N(\%)\end{array}$ & \\
\hline \multicolumn{3}{|l|}{ Use ofManeuver } & \multirow[t]{3}{*}{0,667} \\
\hline Yes & $5(55,6)$ & $4(44,4)$ & \\
\hline No & $4(66,7)$ & $2(33,3)$ & \\
\hline \multicolumn{4}{|l|}{ Effective Maneuver } \\
\hline Yes & $3(42,9)$ & $4(57,1)$ & \multirow[t]{2}{*}{$0,09 \mid$} \\
\hline No & $3(100,0)$ & $0(0,0)$ & \\
\hline \multicolumn{4}{|l|}{ Type ofManeuver } \\
\hline Multipleswallowing & $3(50,0)$ & $3(50,0)$ & \multirow[t]{4}{*}{0,290} \\
\hline Reflexcough & $2(100)$ & $0(0,0)$ & \\
\hline Head backwards & $0(0,0)$ & $\mid(100,0)$ & \\
\hline $\begin{array}{l}\text { Multiple swallo- } \\
\text { wing + Cough }\end{array}$ & $1(100.0)$ & $0(0,0)$ & \\
\hline \multicolumn{4}{|l|}{ Gender } \\
\hline Female & $4(50,0)$ & $4(50,0)$ & \multirow[t]{2}{*}{0,398} \\
\hline Male & $5(7 \mid, 4)$ & $2(28,6)$ & \\
\hline
\end{tabular}

* Statistically significant values Chi-square test.

Table 5. Variables correlation: dysphagia degree, Rosenbeck scale, presence of penetration or aspiration.

\begin{tabular}{|c|c|c|c|}
\hline Analysedvariables & $n$ & Spearman & $\mathrm{p}^{*}$ \\
\hline $\begin{array}{l}\text { Dysphagia degree } \\
\text { and Rosenbeck } \\
\text { Dysphagia degree and }\end{array}$ & 15 & $-0,777067$ & $0,000653 *$ \\
\hline $\begin{array}{l}\text { penetration presence } \\
\text { Dysphagia degree and } \\
\text { aspiration presence }\end{array}$ & 15 & $\begin{array}{l}-0,763359 \\
-0,6|474|\end{array}$ & $\begin{array}{l}0,000928 * \\
0,0 \mid 4739 *\end{array}$ \\
\hline
\end{tabular}

*Statistically significant values Spearman correlation test.

Table 6. Variables correlation: stasis, Rosenbeck scale, penetration and aspiration.

\begin{tabular}{lccc}
\hline Analysed variables & $\mathrm{n}$ & Spearman & $\mathrm{p}^{*}$ \\
\hline Stasis and Rosenbeck & I5 & 0,485786 & 0,066380 \\
Stasis and penetration presence & I5 & 0,492366 & 0,062252 \\
Stasis and aspiration presence & I5 & 0,320256 & 0,244539 \\
\hline
\end{tabular}

*Statistically significant values Spearman correlation test.

variability. Another research (22) also said that studies that equate swallowing of men and women do not indicate differences in the measures that rely on preferred mode of the sensory stimuli, such as the start site of the pharyngeal phase. This can be observed in this sample, since there was no significant difference between the genders in the analyzed data. 
Although patients have not shown clinical signs of dysphagia, history of recurrent pneumonia became an issue to be investigated in view of that, this may be an indicator of symptoms of dysphagia related to oesophageal and pharyngeal phase of swallowing (23) in this sample.

With the use of videofluoroscopy as a method of instrumental assessment of dysphagia, it was possible to visualize the anatomy, physiology and the swallowing process, being also possible through this information to determine which therapeutic procedures can also be effective in relation to the found problem (24) as the effectiveness of the maneuver of multiple swallowing in these cases.

Regarding the presence of dysphagia, $20 \%$ of patients presented mild dysphagia and others (13.4\%) presented mild to moderate and moderate dysphagia. It is important to highlight that changes in breathing pattern, presented by patients with chronic cough may alter the coordination between breathing and swallowing, being that this change will affect the essential timing for the protection of the inferior airway (25), which can be crucial in dysphagia disease.

The analysis of presence of penetrations and laryngeal aspirations (19) revealed the presence of 1 degree in most evaluated patients which will establish the relationship with the degree of dysphagia (18), since the closer to the normality is the swallowing, the absent or lower will be the degree of found aspiration/penetration.

However, two patients present eight degree (19), demonstrating the presence of silent aspiration. The presence of silent aspiration may be linked to the reduction of respiratory strength and of the ability to clean the airway, thus compromising the protection of the same (26). Eating and breathing are acts that are closely integrated, so it is essential to focus on the patient's swallowing, especially on those that present pulmonary diseases (27).

Among the lung disorders found in this study, the chronic cough was more prevalent in relation to other pathologies. It can be sort the chronic cough as the first symptom for the diagnosis of COPD (chronic obstructive pulmonary disease) (23), so this should be considered a symptom and its cause must be investigated before the treatment establishment (28).

The previous diagnosis of lung disorders is important and requires interdisciplinary care. Notably in this study, it is perceived the relationship between the lung disease and the aspiration risk, attested by the findings found during the VFL (29).
A recent study (22) showed that the quantification of the oral or pharyngeal stasis (defined as a residue in the oral cavity, in the pharynx during swallowing) in the videofluoroscopic assessment is limited to a subjective character. Although the tests of association and correlation of the stasis variable did not present significance, it is important to note that the literature (30) shows that there is still no consensus on the form of analysis, definition and stasis degree, which can diversify according to each researcher. Another study (31) concluded that the risk of aspiration increases proportionally with the amount of stasis. Moreover, there is no agreement between the ways of measuring this variable, either subjectively or objectively. Thus, the fact of not presenting significance in the analyses in relation to stasis, it does not rule out the importance of this investigation, but reinforces the need to continue with investigations of this variable in the process of swallowing.

The correlation analysis between the presence/ absence of stasis, the type of maneuvers used and their effectiveness, become essential for prognosis and for the definition of the speech therapy to be performed.

It is noteworthy that by subjecting the patient to radiation in the examination of VFL, as well as by understanding the dynamics of swallowing, it is essential for the Speech Language Pathologist to try therapeutic maneuvers to seek greater efficiency and accuracy in treating patients with risk of aspiration. Despite not presenting statistical significance, the maneuver of multiple swallowing seems to be the most appropriate and effective in these cases.

\section{CONCLUSION}

The analysis of the swallowing pharyngeal phase in patients with chronic cough reveals that there are peculiarities in the swallowing functioning of this population, despite not presenting complaints relating to swallowing, it presents important aspiration risk due to the presence of changes in breathing pattern that can intervene in the coordination between breathing and swallowing, which is essential for the protection of the lower airway. However, there are recommended studies with larger samples that allow more inferences on this issue.

\section{REFERENCES}

1. Prodomo LPV, Angelis Ec, Barros ANP. Avaliação clínica fonoaudiológica das disfagias. In: Jotz GP, Angelis EC, Barros APB. Tratado da deglutição e disfagia: noadulto e na criança. Rio de Janeiro: Revinter, 2010. cap 6. p. 61-67. 
2. Marchesan IQ. O que se considera normal na deglutição. In: Jacobi JS, Levy DS, Silva LMC. Disfagia avaliação e tratamento. Rio de Janeiro: Revinter, 2003. cap 1. p.318.

3. Andrade CRF. Processamento motor- Padrão de organização da mastigação e deglutição. In: Andrade CRF, Limongi SCO. Disfagia prática baseada em evidências. São Paulo: Sarvier, 2012. cap.3. p. 24-31.

4. Jotz GP, Dornelles S. Fisiologia da deglutição. In: Jotz GP, Angelis EC, Barros APB. Tratado da deglutição e disfagia: no adulto e na criança. Rio de Janeiro: Revinter, 2010. cap. 2. p.16-20.

5. Gonçalves MIR, César SR. Disfagias neurogênicas: Avaliação. In: Ortiz, KZ. (Org). Distúrbios neurológicos adquiridos. Barueri - SP: Manole, 2010. c. 14. p. 278-301.

6. Silva RG. Disfagia orofaríngea pós acidente vascular encefálico. In: FERREIRA, LP etal. Tratadode Fonoaudiologia. São Paulo: Roca, 2004. cap.5. p. 354-355.

7. Souza BBA et al. Nutrição e disfagia: Guia para profissionais. Curitiba - PR: Nutroclínica, 2003. cap.5. p. 17-22.

8. Swanson PB, Carrau RL, Murry T. Avaliação da deglutição com fibroendoscópio - FEES. In: Jotz GP, Angelis EC, Barros APB. Tratado da deglutição e disfagia. Rio de Janeiro: Revinter, 2010. cap. 9. p. 76-81.

9. Miller CD, Rebuck JA, Ahern JW, Rogers FB. Daily evaluation of macroaspiration in the critically Ill post-trauma patient. Current Surgery. 2005; 62 (5): 504-508.

10. Marik PE. Primary Care: Aspiration pneumonitis and aspiration pneumonia. The New England Journal of Medicine. 2001; 334 (9): 665-671.

11. Lopes FO. Tratado de Fonaudiologia. São Paulo: Tecmedd, 2005. 2ed.

12. Fleming CM, Shepard JO, Mark EJ. Case 15-2003: A 47year-old man with waxing and waning pulmonary nodules five years after treatment for testicular seminoma. The New England Journal of Medicine.2003. 348 (20): 2019-2027.

13.Gross RD, AtwoodJrCW, Ross SB, OlszewskiJW, Eichhorn KA. The coordination of breathing and swallowing in chronic obstructive pulmonary Disease. Am J Respir Crit Care Med. 2009; 179 (7): 559-65.

14.Palombini BC et al. Recentes progressos no diagnóstico diferencial da tosse crônica. Rev Bras Clín Ter. 1997; 23(2):402.
15.Andrade CRF. Prática Baseada em Evidência na Disfagia. In: Andrade CRF, Limongi SCO. Disfagia Prática Baseada em Evidências. São Paulo: Sarvier, 2012. cap. 1. p. 3-6.

16. Cardoso MCAF, Fontoura EG. Valor da auscuta cervical em pacientes acometidos por disfagia neurogênica. Arq. Int. Otorrinolaringol. 2009; 13 (4): 431-9.

17. Furkim, AM. Silva, RG. Programas de Reabilitação em Disfagia Neurogênica. In: Furkim, AM, Santini, CS. Disfagias Orofaríngeas. São Paulo: Pró - Fono; 1999.

18. O’Neil KH, Purdy M, Falk J, Gallo L. The dysphagia outcome and severity scale.Dysphagia. 1999; 14: 139-145.

19. Rosenbek JC, Robbins JA, Roecker EB, Coyle JL, Wood JL. A penetration-aspiration scale. Dysphagia. 1996; 11: 938.

20. Paintal HS, Kuschner WG. Aspiration syndromes: 10 clinical pearls every physician should know. International Journal of Clinical Practice. 2007; 61 (5): 846-852.

21. Dantas RO, Cassiani RA, Santos CM, Gonzaga GC, Alves LMT, Mazin SC. Effect of gender on swallow event duration assessed by videofluoroscopy. Dysphagia. 2009; 24:2804 .

22. Prodomo LPV. Caracterização videofluoroscópica da fase faríngea da deglutição [ tese de doutorado]. São Paulo (SP): Fundação Antonio Prudente; 2010.

23. Chaves RD, Carvalho CRF, Cukier A, Stelmach R, Andrade CRF. Indicadores de disfagia na doença pulmonar obstrutiva crônica. In: : Andrade CRF, Limongi SCO. Disfagia Prática Baseada em Evidências. São Paulo: Sarvier, 2012. cap.13. p. 151-166.

24. Kolb G, Bröker M. State of the art in aspiration assessment and the idea of a new non invasive predictive test for the risk of aspiration in stroke. The Journal of Nutrition, Health \& Aging( ). 2009; 13 (5): 429-433.

25. Kijima M, Isono S, Nishino T. Coordination of swallowing and phases of respiration during added respiratory loads in awake subjects. American Journal of Respiratory and Critical Care Medicine. 1999; 159: 1989-1902.

26. Coelho CA. 1987 apud Chaves RD, Carvalho CRF, Cukier A, Stelmach R, Andrade CRF. Sintomas indicativos de disfagia em portadores de DPOC. J Bras Pneumol. 2011;37(2):176183.

27. Silva LMC, Jacobi JS. Disfagia orofaríngea e sua importância na pneumologia. In: Jacobi JS, Levy DS, Silva LMC. Disfagia 
avaliação e tratamento. Rio de Janeiro: Revinter, 2003. cap. 12. p. $163-180$.

28. Person OC, Cerchiari DP, Zanini RVR, Santos RO, Rapoport PB. Cisto de base de língua como causa de tosse crônica. Arq Med ABC. 2005; 31 (1): 35-7.

29. Langmore SE, et al. Predictors of aspiration pneumonia: how important is dysphagia? Dysphagia. 1998; 13 (2): 6981.
30. DyerJC, Leslie P, Drinnan MJ. Objective computer-based assessment of valleculae residue-is it useful? Dysphagia. 2008; 23 (1): 7-15.

31. Eisenhuber E, et al. Videofluoroscopic assessment of patients with dysphagia: Pharyngeal retention is a predictive factor for aspiration. AJR Am J Roentgenol. 2002; 178 (2): 393-8. 